\title{
CHANGES IN QUANTITATIVE EEG ABSOLUTE POWER DURING THE TASK OF CATCHING AN OBJECT IN FREE FALL
}

\author{
Sergio Machado 1,5 , Cláudio Elidio Portella', Julio Guilherme Silva ${ }^{1,5}$, \\ Bruna Velasques ${ }^{1,5}$, Patrícia Terra ${ }^{3}$, Camila Ferreira Vorkapic', \\ Vernon Furtado da Silva ${ }^{3}$, Luis Miana ${ }^{3}$, Luis Basile ${ }^{4}$, Mauricio Cagy ${ }^{1,5}$, \\ Roberto Piedade ${ }^{1,5}$, Pedro Ribeiro ${ }^{1,2,3,5}$
}

\begin{abstract}
The aim of this study was to verify changes in absolute power ( $q E E G$ ), in theta, during the catch of a free falling object. The sample consisted of 10 healthy individuals, of both genders, with ages between 25 and 40 years. A three-way ANOVA followed by Post-Hoc analysis was applied. The results demonstrated main effects for time and position. In conclusion, a motor task that involves expectation produces deactivation of non-relevant areas in the ipsilateral hemisphere of the active limb. On the other hand, the patterns of results showed activation in areas responsible for planning and selection of motor repertories in the contralateral hemisphere.
\end{abstract}

KEY WORDS: absolute power, qEEG, planning, sensorimotor integration.

\begin{abstract}
Mudanças na potência absoluta no EEG quantitativo durante tarefa de apreensão de um objeto em queda livre

RESUMO - O objetivo deste estudo foi verificar mudanças na potência absoluta ( $E E G q)$, em teta, durante a pegada de objeto em queda livre. A amostra consistiu de 20 indivíduos saudáveis, de ambos os gêneros, com idade entre 25 e 40 anos. Foi utilizada uma ANOVA three-way seguida de uma análise Post-Hoc. Os resultados demonstraram efeito principal para momento e posição. Concluindo, uma tarefa motora que envolve expectativa produz desativação de áreas não-relevantes no hemisfério ipsilateral do membro ativo. Por outro lado, o padrão dos resultados mostrou ativação em áreas responsáveis por planejamento e seleção de repertórios motores no hemisfério contralateral.
\end{abstract}

PALAVRAS-CHAVE: potência absoluta, EEGq, planejamento, integração sensório-motora.

Motor behavior is the product of a fine integration between cortical and peripheral components associated to afferent information. The central nervous system (CNS) captures, identifies and processes sensory stimuli in order to prepare and adjust motor behavior ${ }^{1}$. The prefrontal cortex (PFC) is an integration cortex. It is considered neither a sensory nor a motor cortex; it is an association region, providing integration sensory stimuli to motor centers ${ }^{2,3}$. The PFC is involved in cognition, attention maintenance, planning and organization, including the capacity to follow certain thought sequences and behavior strategy choices ${ }^{4}$. Plastic alterations might occur in this area regarding motor reactions (reaction time, anticipatory movements and motor learning), which might lead to performance and gesture precision improvement ${ }^{5}$.

Quantitative electroencephalography ( $q E E G$ ) has made possible the elucidation of cognitive processes and motor learning ${ }^{6,7}$. Specific electroencephalographic variables are particularly related to such processes. Absolute power, defined as total energy intensity of an electrode on a certain region at different frequency bands ${ }^{8}$. Therefore, the present study examined the theta band $(4-7 \mathrm{~Hz})$, due to its relation with attention processes, particularly, sustained attention ${ }^{9}$. Previous experimental data showed an association between theta and cognitive and visual-

\footnotetext{
'Laboratório de Mapeamento Cerebral e Integração Sensório-Motor, Instituto de Psiquiatria, Universidade Federal do Rio de Janeiro, Rio de Janeiro RJ, Brazil (IPUB/UFRJ); ${ }^{2}$ Departamento de Biociências da Atividade Física, Escola de Educação Física e Desportos (EEFD/UFRJ); ${ }^{3}$ Universidade Castelo Branco (PROCIHM); ${ }^{4}$ Departamento de Psiquiatria, Faculdade de Medicina, Universidade de São Paulo, São Paulo SP, Brazil (USP); ${ }^{5}$ Instituto Brasileiro de Biociências Neurais (IBBN).
}

Received 9 November 2006, received in final form 9 February 2007. Accepted 3 April 2007.

Dr. Sergio Eduardo de Carvalho Machado - Rua Professor Sabóia Ribeiro 69 / 104 - 22430-130 Rio de Janeiro RJ - Brasil. E-mail: secm80@ig.com.br 
spatial tasks ${ }^{10}$. Such tasks involve dynamic and complex sensory-motor integration processes ${ }^{11}$.

This study aimed at trying to elucidate electrophysiological and cortical mechanisms involved in anticipatory actions when individuals had to catch a free falling object; specifically through qEEG theta absolute power changes.

\section{METHOD}

The sample was composed for 20 healthy individuals of both sexes with ages varying between 25 and 40 years, absence of mental and physical illness (previous anamnesis), right handed (Edinburgh), and do not using any psychoactive or psychotropic substance at the time of the study. The experiment consisted of a task of catching an object in free fall. The balls were discharged by an electromagnetic system, composed of two solenoids. The interval between the

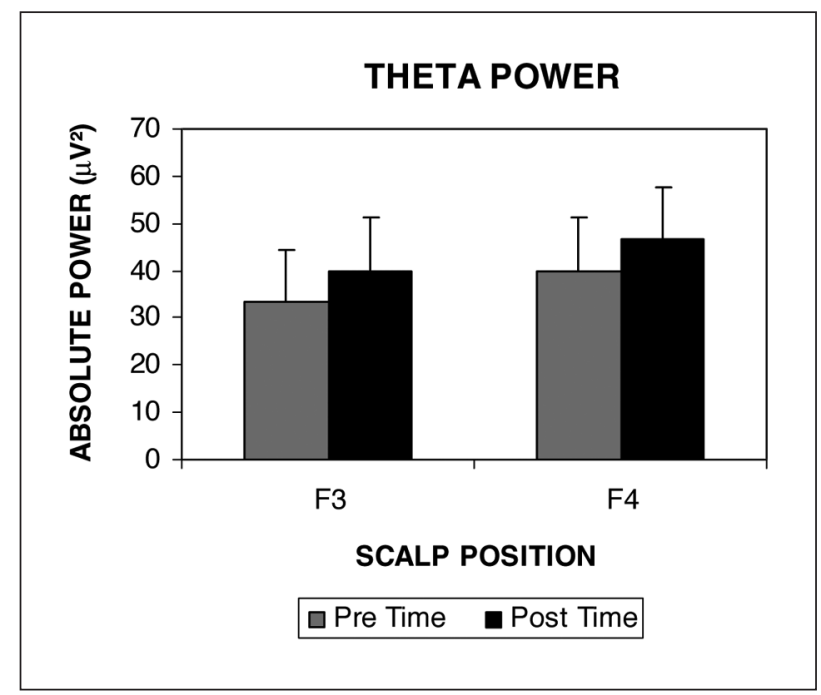

Fig 1. Absolute power means in theta frequency band between F3 and F4 positions in prefrontal cortex in pre and post time.

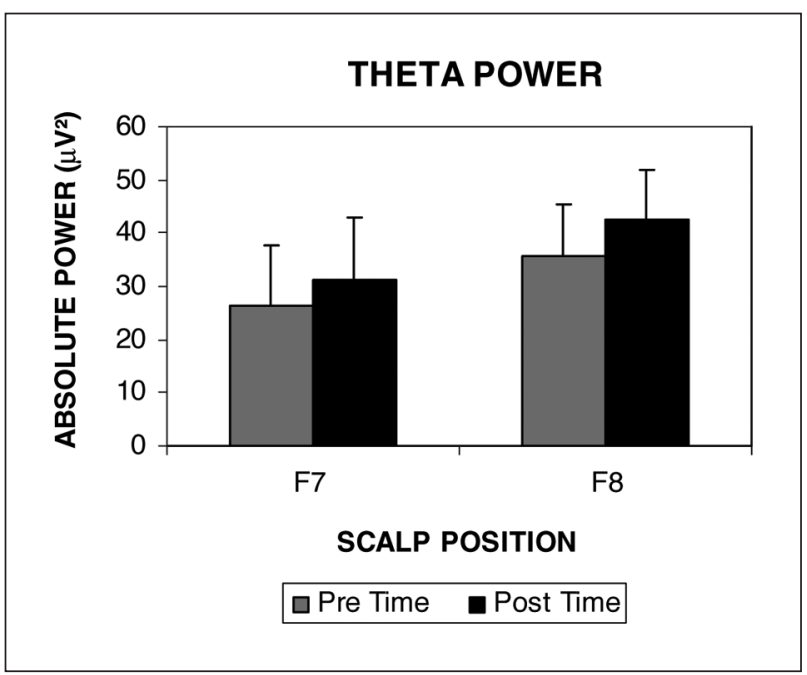

Fig 2. Absolute power means in theta frequency band between F7 and F8 positions in prefrontal cortex in pre and post time. falling balls was 11 seconds, each ball was a trial and each block was made of 15 trials. The entire experiment consisted of three blocks, lasting 2 min and 30 sec each, with 1 min interval between the blocks. The intervals favored the recovery of the active limb, avoiding muscular fatigue. The qEEG acquisition occurred during 2 seconds before the ball fall and 2 seconds after the ball fall ${ }^{12}$.

Spatial electrode localization and frequency bands - Since motivation, planning and execution of voluntary movements are mediated by the frontal lobes ${ }^{13,14}$, the frontal area was investigated in the present study. Electrodes investigated were: F7, F3, FZ, F8, F4. The theta band (4-7 $\mathrm{Hz}$ ) was also chosen due to its association with attention processes particularly sustained attention ${ }^{9}$, and space-visual tasks ${ }^{10}$.

Statistical analysis - A Three-Way ANOVA and a Post Hoc were used for each electrode combination. The factors time (pre and post ball fall) blocks (whole task time) and position (the three electrode combinations) a) F3/F4; b) F7/ F8; and c) F3F7/F4F8, were compared ( $\mathrm{p} \leq 0.05)$.

\section{RESULTS}

In the first analysis, when the left prefrontal cortex was compared to the right prefrontal cortex (F3/ $F 4)$, one main effect for the factors time $(p=0.002)$ and position ( $p=0.002$ ) (Fig 1) was observed. In the second analysis, when the left prefrontal cortex was compared to the right prefrontal cortex (F7/F8), another main effect was observed for time $(p=0.006)$ and position ( $p=0.000$ ) factors (Fig 2). In the third analysis, when the left prefrontal cortex was compared to the right prefrontal cortex (F3F7/F4F8), an additional main effect for the time $(p=0.002)$ and position ( $p=0.000$ ) factors was observed (Fig 3 ). No interactions among effects were detected.

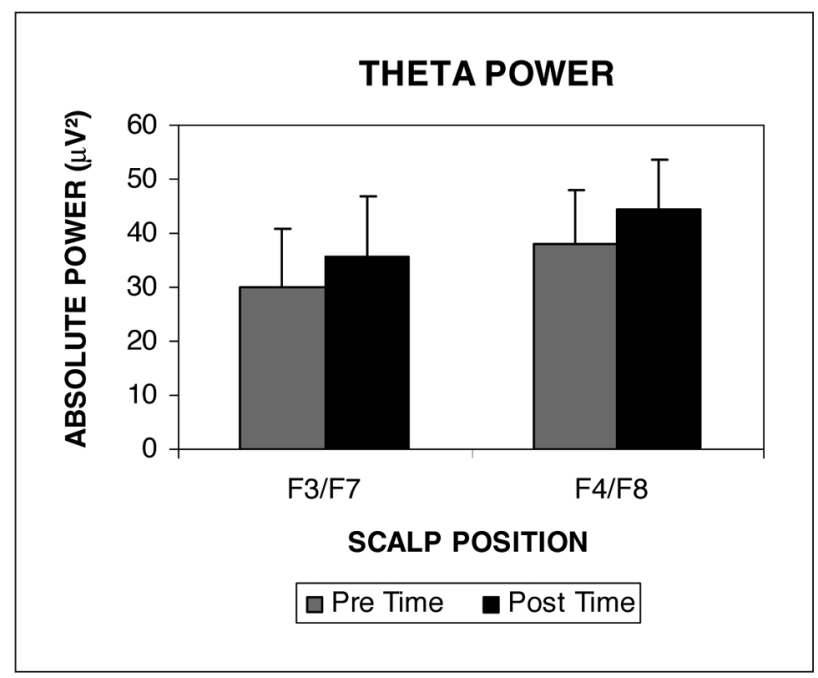

Fig 3. Absolute power means in theta frequency band between F3/ F7 and F4/F8 positions in prefrontal cortex in pre and post time. 


\section{DISCUSSION}

The current experiment is an attempt to elucidate cortical/electrophysiological mechanisms regarding anticipatory actions involved in voluntary movements, specifically, when subjects had to catch a free falling object (in this case, a ball). Through qEEG, changes in the theta frequency band power were examined. No interactions among the factors were observed, so discussion will only refer to the main effects.

Time factor - In this experiment, subjects had to observe the fall of a certain object with the objective of catching it. An electromagnetic system, made of two solenoids, was positioned ahead of the subjects in order to send information about the pre and post fall time to the computer ${ }^{12}$. Results demonstrated a theta absolute power increase in the post fall period, when compared to the pre fall period. This increase suggests a decrease in neural activity and consequently a reduced readiness engagement subsequent to the task. Inversely, the period before the object fall revealed a diminished power value, which seems to reflect an increase in neural activity. This might suggest increased expectation, alertness and readiness ${ }^{15}$ when the object was falling. Our data are in agreement with previous investigation showing reduced theta values in the pre-stimulus period and increased theta values in the post stimulus period during continuous motor activities ${ }^{10}$.

Position factor - Differences in absolute power values between the left prefrontal and the right prefrontal cortices were observed. According to our results, there was a theta absolute power augmentation when certain regions were isolated, F3/F4, and F7/F8; and when electrodes were summed F3F7/F4F8. Considering that a theta power increase could be interpreted as a deactivation of the involved cortical area, the power augmentation observed in the right hemisphere suggests disengagement during the task. Traditionally, the right hemisphere is related to spatial functions such as memory, learning and orientation ${ }^{16-18}$. A specialization of the right hemisphere in spatial functions might be related to (spatial) attention control of visual representation ${ }^{19,20}$, or a regulation function in conflict situations ${ }^{21}$, as when experiencing a bad interaction between motor and proprioceptive interaction and/or visual feedback ${ }^{22}$.

Hatfield et al. ${ }^{23}$ observed, through EEGq, an alpha power increase in the left hemisphere of elite shooters during the preparatory period and even after the shot was fired. Besides, this alpha power increase was followed by relative power stability in right hemisphere. Alpha power has an inverse relationship with cortical activation. High power values means diminished neuronal activity ${ }^{23,24}$. Investigations in motor performance area reveal that an alpha power increase remains relatively stable or even decreases in the right hemisphere during the preparatory period, suggesting that these regions could be highly activated during the preparatory phase of complex motor tasks $\mathrm{s}^{25}$. Considering the hypothesis that theta presents the same behavior as alpha, our findings suggest an activation of the responsible areas for planning and selection of motor patterns in the contralateral hemispheres of the active limb. It also suggests a deactivation of non relevant areas of the ipsilateral hemisphere.

Thalamic structures (interaction between thalamic nuclei and thalamic reticular nucleus) activate specific cortical areas at a certain time of the relevant information processing and deactivate others not used during the task execution ${ }^{26}$. Such process could be interpreted as an electroencephalographic correlate of activated cortical areas involved in the sensory information processing and motor behavior production ${ }^{27}$. This might indicate a participation of a broader neural network in the information processing ${ }^{28}$.

In conclusion, our findings demonstrate that the execution of a motor task involving expectation, such as an object fall, produces deactivation of non relevant areas in the ipsilateral hemisphere of the utilized limb. An activation of responsible areas for planning and motor pattern selection was also observed in the contralateral hemisphere of the utilized limb. Different population, other than healthy subjects, should also be considered for new experiments, for example, patients suffering from Alzheimer's and Parkinson's disease, in an attempt to observe specific variables such as attention, anticipatory movements, reaction time and motor planning and execution.

\section{REFERENCES}

1. Nargeot R. Votage-dependent switching of sensorimotor integration by a lobster central pattern generator. J Neurosci 2003;23:4803-4808.

2. Miller EK, Cohen JD. An integrative theory of prefrontal cortex function. Annu Rev Neurosci 2001;24:167-202.

3. Roland P, Larsen B, Lassen N, Skinhoj E. Supplementary motor area and other cortical areas in organization of voluntary movements in man. J Neurophysiol 1980;43:118-136.

4. Koechlin E, Basso G, Pietrini P, Panzer S, Grafman J. The role of the anterior prefrontal cortex in human cognition. Nature 1999;399:148-151.

5. Karni A, Meyer G, Rey-Hipolito C, et al. The acquisition of skilled motor performance: fast and slow experience-driven changes in primary motor cortex. Proc Natl Acad USA 1998;95:861-868.

6. Hung T, Saarela P, Hatfield B. Eletroencephalography and mental states associated with elite performance. J Sport Exerc Psychol 1998;20:35-53.

7. Smith ME, Mcevoy L, Gevins A. Neurophysiological indeces of strategy development and skill acquisition. Brain Res Cogn Brain Res 1999; 7:389-404. 
8. Cunha M, Bastos VH, Veiga $H$, et al. Alterações na distribuição de potência cortical em função da consolidação da memória no aprendizado de datilografia. Arq Neuropsiquiatr 2004;62:662-668.

9. Portella C, Silva JG, Bastos VH, et al. Aprendizagem de procedimento e efeitos ansiolíticos: medidas eletrencefalográficas, motora e atencional. Arq Neuropsiquiatr 2006;64:478-484.

10. Caplan JB, Madsen JR, Schulze-Bonhage A, Aschenbrenner-Scheibe R, Newman EL, Kahana MJ. Human theta oscillations related to sensorimotor integration and spatial learning. J Neurosci 2003;23:4726 -4736.

11. Tesche CD, Karhu J. Interactive processing of sensory input and motor output in the human hippocampus. J Cogn Neurosci 1999;11:424-436

12. Portella CE, Silva JG, Machado S, et al. Eeg spectral coherence inter and intrahemispheric during a catching object fall task. Arq Neuropsiquiatr 2007;65:63-67.

13. Koechlin E, Corrado G, Pietrini P, Grafman J. Dissociating the role of the medial and lateral anterior prefrontal cortex in human planning. Proc Natl Acad Sci USA 2000;97:7651-7656.

14. Barry R, Clarke A, McCarthy R, Selikowitz M, Johnstone S. EEG coherence adjusted for inter-electrode distance in children with attentiondeficit/hyperactivity disorder. Int J Psychophysiol 2005;58:12-20.

15. Gomez CM, Vaquero E, Lopez-Mendoza D, Gonzalez-Rosa J, VazquezMarrufo M. Reduction of EEG power during expectancy periods in humans. Acta Neurobiol Exp 2004;64:143-151.

16. Coull JT, Nobre AC. Where and when to pay attention: the neural systems for directing attention to spatial locations and to time intervals as revealed by both PET and fMRI. J Neurosci 1998;998:7426-7435.

17. Garavan H, Ross TJ, Stein EA. Right hemisphere dominance of inhibitory control: an event- related functional MRI study. Proc Natl Acad Sci USA 1999;96:8301-8306.

18. Ghilardi MF, Ghez C, Dhawan V et al. Patterns of regional brain activation associated with different forms of motor learning. Brain Res 2000; 871:127-145.
19. Corbetta M, Miezin FM, Shulman GL, Petersen SE. A PET study of visuospatial attention. J Neurosci 1993;13:1202-1226.

20. Mesulam MM. Spatial attention and neglect: parietal, frontal and cingulate contributions to the mental representation and attentional targeting of salient extrapersonal events. Phil Trans R Soc Lond B Sci 1999; 354:1325-1346.

21. Wenderoth N, Debaere F, Sunaert S, van Hecke P, Swinnen, SP. Parieto-premotor areas mediate directional interference during bimanual movements. Cereb Cortex 2004;14:1153-1163.

22. Fink GR, Marshall JC, Halligan PW, et al. The neural consequences of conflict between intention and the senses. Brain 1999;122:497-512.

23. Hatfield BD, Landers DM, Ray WJ. Cognitive processes during selfpaced motor performance: an electroencephalographic profile of skilled marksmen. J Sport Exerc Psychol 1984;6:42-59.

24. Lawton GW, Hung TM, Saarela P, Hatfield BD. Electroencephalography and mental states associated with elite performance. J Sport Exerc Psychol 1998;20:35-53.

25. Crews DJ, Landers DM. Electroencephalographic measures of attentional patterns prior to the golf putt. Med Sci Sports Exerc 1993;25:116-126.

26. Suffczynski P, Pijn JMP, Pfurtscheller G, Lopes da Silva FH. Event-related dynamics of alpha band rhythms: a neuronal network model of focal ERD/surround ERS. In Pfurtscheller G, Lopes da Silva FH (Eds). Event-related desynchronization handbook of electroencephalography and clinical neurophysiology, vol. 6. revised edition, Amsterdam: Elsevier, 1999:67-85.

27. Pfurtscheller G, Klimesch W. Functional topography during a visuoverbal judgement task studied with event-related desynchronization mapping. J Clin Neurophysiol 1992;9:120-131.

28. Dujardin K, Derambure P, Defebvre L, Bourriez JL, Jacquesson JM, Guieu JD. Evaluation of event-related desynchronization (ERD) during a recognition task: effect of attention. Electroenceph Clin Neurophysiol 1993;86:353-356. 